\title{
Swedish tribalism and Tanzanian entrepreneurship: preconditions for trust formation
}

\author{
Malin Tillmar
}

\section{Linköping University Post Print}

\section{Tweet}

N.B.: When citing this work, cite the original article.

This is an electronic version of an article published in:

Malin Tillmar, Swedish tribalism and Tanzanian entrepreneurship: preconditions for trust formation, 2006, Entrepreneurship and Regional Development, (18), 2, 91-107.

Entrepreneurship and Regional Development is available online at informaworldTM: http://dx.doi.org/10.1080/08985620500531956

Copyright: Taylor \& Francis (Routledge): SSH Titles http://www.routledge.com/ 


\title{
Swedish Tribalism and Tanzanian Entrepreneurship: \\ Preconditions for trust formation
}

\author{
Malin Tillmar, Ph.D. Ass. Prof. \\ Department of Management and Economics \\ Linköping University \\ S-583 81 LINKÖPING \\ SWEDEN \\ e-mail: malti@eki.liu.se \\ tel: +4613281588 \\ National Institutet for Working Life \\ Laxholmstorget 3 \\ S-602 21 NORRKÖPING \\ e-mail: malin.tillmar@arbetslivsinstitutet.se \\ tel: +4611218914 \\ fax: +4611218920
}




\title{
Swedish Tribalism and Tanzanian Entrepreneurship:
}

\section{Preconditions for trust formation}

\begin{abstract}
This paper sets out to explore the preconditions for trust formation using a comparative approach. It takes an empirical point of departure, in two longitudinal and ethnographically inspired studies in the differing contexts of Sweden and Tanzania. The comparison reveals many similarities between the contexts with regard to the influence of informal institutions, as well as the significance of categories in trust formation. Perhaps surprisingly, trust and cooperation are not as low as could be expected in Tanzania, given the inadequate formal institutional environment, but instead, the greater need for cooperation evoked entrepreneurial initiatives that enabled the creation of trust. While the Swedish small-business owners could afford their 'tribalism', Tanzanians created trust in an entrepreneurial way. The importance of interventions to understand the local institutional framework is highlighted and it is argued that arranging business training, or similar events, is a fruitful way to facilitate the trust creation process in development contexts.
\end{abstract}

Key words: Trust, Cooperation, Entrepreneurship, Institutions 


\section{Introduction}

\section{Karlshöjden, Sweden, November 1997}

One cold and dark evening in the middle of November, ten owners of small tourism companies in northern Karlshöjden gather at Maria's place. As the cars arrive, Martin, the project manager, greets people in the courtyard with a grave face. The atmosphere is tense. Whispers are heard about conflicts and emergency meetings.

As coffee is served in the kitchen of the manor house, those who have gathered greet each other. Not everyone has met Nicklas and Nina, who have recently moved out to Karlshöjden. The subject of today's meeting is to put together local tourist attraction packages to appeal to companies offering bus trips. Maria, Elisabeth and Annika enthusiastically start to put ideas across about how services could be combined. The tense atmosphere is gone.

Just when the meeting is about to end, Nina announces that she and Nicklas have something to say. The tense atmosphere is back. A few people round the kitchen table stiffen and glance at each other. Nina informs those present in a matter of fact manner that she and Nicklas have started a new booking office for tourists in Karlshöjden. The brief presentation is enough to make people understand that their software can provide more advanced services than those currently offered by the local tourist office. As soon as she has finished, Martin quickly raises the next point on the agenda. The conflict must not come to the surface.

\section{Singida, Tanzania, April 2000}

The hot sun is approaching its zenith and Mama Mmari is dusting the spare parts for radios and bikes which are stored behind the counter in her small shop. The short rain period never 
came and the long rains have not yet started. There is sand everywhere. At this time of the year there are few customers and Mama Mmari, who is attending a business training programme, is putting her efforts into longer term enhancement of her business activities. Through a cooperative project, she wants to start buying and selling crops. This sort of business is profitable but labour intensive. Starting a cooperation is easier said than done. People are afraid of cooperation and Mama Mmari is struggling against a headwind. The police and the court system are not to be counted on due to corruption. Prejudices based on tribal affiliation and gender prevail and people are afraid that their fellow business owners may practice witchcraft. Henry Madarka is one of the few who believes in the idea. He assists Mama Mmari in her efforts but says:

'If there were any people with good characteristics ... but it is difficult. Some people are worried, others will soon just disappear and others are drunkards.'

Getting the right people interested in the crop business, which was Mama Mmari's original idea, wasn't possible but Mama Mmari and Henry did not give up the idea of cooperation. They eventually managed to start a Savings and Credit Cooperative Society together with fourteen other business owners.

The preconditions in the situations described above are very different. Yet, in both areas, small-businesses that are receiving regional development support, struggle to facilitate cooperation, but encounter problems of trust.

Within research on entrepreneurship and small-business, and not the least among those focusing on networks and clusters (cf. Saxenian 1994, Maillat 1995, Johannisson 1995, 2002, Bachmann 2003), the importance of cooperation and trust is often either mentioned or is present as an underlying assumption. Trust is a component of the social capital (Coleman 
1988) often referred to. Within the multidisciplinary field of trust research, the lion's share of the articles are conceptual in nature, and as a result has paid insufficient attention to exploring how trust formation may be contingent on differing contextual circumstances. Empirical studies of trust and cooperation are often undertaken in societies or formal organisations where a stable and reliable macro system of governance and hierarchy prevails (cf. contributions of Powell, Burt and Knez; Zucker et al. 1996, in Kramer and Tyler 1999, as well as Knights et al. and Maguire et al. in the Organization Studies Special Issue 2001). Studies of trust undertaken in non-western contexts (cf. Hagen and Choe 1998, Child and Möllering 2003) and guided by a more cross-cultural approach (Child 2000) indicate that differences in the institutional make-up may be significant and should be taken into account (cf. Bachmann 2000).

This paper takes its point of departure in a comparative cross-cultural and ethnographically inspired study. The aim is to explore, by means of comparison, the contextual preconditions for the trust-formation process. How are we to conceive the 'the rules of the game' and their impact on trust development? What influences these 'rules of the game' and, in this respect, what can we learn from the differences and similarities between the contexts?

Although this paper will emphasize the empirical findings, in order to make more sense to the reader I will first describe the theoretical framework and definitions used, as well as present the methodology. This will be followed by the elaboration of the two case stories. I shall then summarize the findings according to the framework, before highlighting contributions to theory and practice. 


\section{Tentative Framework}

In this section, the concepts involved will be defined and a tentative framework of trust and its prerequisites is proposed. This is a study of small-business owners and their cooperation. The concepts 'business owner' and 'entrepreneur' are not equated in this paper. Business owners may or may not be entrepreneurial. The definition of entrepreneurship used here is inspired by Schumpeter (1934/1994) and focuses on finding new combinations of already existing features. Therefore in this paper, entrepreneurship is conceived as imaginatively creating a new opportunity and then actualising it.

Cooperation is defined as a situation where people act 'in the interest of the collectivity, and refrain from opportunistic actions even though immediate or short term rewards are not forthcoming' (Alvesson and Lindkvist 1993, p.433). All human actions have an inherent component of risk taking, and in cooperation, a large portion of the risk has to do with the actions of others. Trust, inspired by Rousseau et al. (1998) as well as by others, is defined as a 'state of mind of willingness to accept vulnerability to actions of others based on positive expectations of their behaviour' (Tillmar 2002, p.250). The definition is broad, but highlights some important distinctions. Trust is distinguished from gambling in that the positive expectations are based on what is taken to be 'good reasons' (Lewis and Weigert 1985), but there are never any logical proofs involved in trust (Luhmann 1979).

'The rules of the game' (North 1990) are used here as an umbrella term for the various prescriptions of 'how to do things around here' that exist in the societies in which the smallbusiness cooperation is embedded (cf. Granovetter 1985). To use the terms employed by North (1990) the rules of the game depend on formal and informal institutions. Here formal institutions refer to laws, rules and regulations stipulated on a national level. Informal, or 
indigenous institutions are organic and 'evolve spontaneously and unintentionally over time out of human interaction, and they take forms such as codes of conduct, conventions or norms ’ (Havnevik and Hårsmar 1999, p.42).

Among authors who have considered 'the rules of the game' in relation to trust development, some focus on the influence of the formal institutional framework. As early as 1986 Zucker noted that bureaucracies, regulation and insurance mechanisms became important sources of trust in the disrupted US society after 1840. More recently, Deakin and Wilkinson (2000) argued that building of processual trust cannot be regarded in isolation from the institutional framework. Other authors, such as Fukuyama (1996), focus on informal institutions. He argues that trust has cultural roots, i.e. depend on 'inherited ethical habit' (p.34), and stems from the level of spontaneous sociability in a community. In a similar vein, some authors view trust as a component of the social capital of a region (Coleman 1988, Maillat 1995).

As formal and informal institutions influence each other, virtuous and vicious circles of trust in a society may emerge. This has been approached from different angles. As an example, Putnam (1993) argued that citizenship solidarity was important for the functioning of institutions, whereas Sitkin (1995) and Sztompka (1999) argue that formal institutions contribute to the creation of trust. In his macro-level oriented theory of trust Sztompka (1999) discusses the influence of historical tradition and structural context (accountability of persons and institutions, stability of social order etc.) in creating a culture of trust. At the same time, he recognizes the central role of individuals and their social mood (optimism, future and success orientation, trusting impulse etc.) and collective capital (wealth, education, robust family, religious beliefs etc). Sztompka thus combines recognising different institutions while managing to avoid determinism. Sztompka also recognises the vicious and virtuous circles 
that emerge as the culture of trust, in turn, influences historical tradition and structural context. His theory, drawing on examples from a transitional society (Poland), appears meaningful for an analysis of the Tanzanian context. The tentative framework of trust and the dimensions belonging to it presented below is inspired by this theory, in combination with a number of more micro-level oriented theories on trust which are to be found in organisational theory.

Insert Figure 1 -The $\mathrm{t}(\mathrm{h})$ ree dimensions of trust -here

Flourishing cooperation can be regarded as the crown of the tree of trust. The rules of the game in society can be illustrated by the soil out of which the tree of trust grows. Formal and informal institutions are nutrients to this soil, enabling the cooperative tree to survive, grow and flourish. Elsewhere (Tillmar 2002), I have discussed at length the three dimensions; reasons, focal levels and objects. In short, the view taken here is that trust may be based on knowledge of someone's character, but also on safeguards such as the availability of sanctions (Sztompka 1999) and natural hostage situations (Shapiro et al. 1992, Lewicki and Bunker 1995) ${ }^{\mathrm{i}}$. These three reasons for trust may be considered as the roots of the tree. The trunk of the tree is composed of three building blocks, related to three levels that trust may focus on, general (Fukuyama 1996), category (Pettersson 1999) and specific (cf. Lewicki and Bunker 1995, Ring 1996). This symbolises that the trustor's trust in someone may not only be related to the specific person, but also to trust in the category to which he/she belongs as well as to general trust in people in a given society. The trunk of trust then divides into three branches relating to the trusted behaviour of the trustee. That is to say, trust may concern the idéa that the trustee’s behaviour reflects goodness (or benevolence), capability (cf. Nooteboom 1996) 
and/or commitment (Pettersson 1999). Trust in a given cooperation is often based on a variety of reasons, exists on various levels, and is directed at various objects in combination.

\section{Methodology}

This article is built on two rather extensive qualitative studies rendered in more detail elsewhere (Tillmar 2002). Below, the methodology used in the two separate studies and the reflections relating to the research process as a whole will be discussed.

\subsection{Using divergent cases}

Understanding how various rules of the game affect preconditions for trust and cooperation can be facilitated by contrasting two divergent contexts. As Ragin (1989) argues, case study oriented comparisons 'provide a powerful basis not only for identifying causes but also for differentiating among important types and subtypes of social phenomena' (p.43-44). Crosscultural studies also help to reveal and explain patterns of behaviour which we would not be able to identify without an alternative pattern to provide a contrast (Brislin 1980, Stewart et al. 1994). Bachmann (2000) also puts cross-national and comparative studies high on the research agenda, due to the need to understand how trust is influenced by different elements of the institutional framework and how they interact with each other.

\subsection{The Swedish case}

The Swedish study focuses on business owners linked to a tourism association in an area that is here fictitiously called Karlshöjden. The association had received EU-funding for a project aimed at developing the tourism industry in the area. Observations, in combination with 24 interviews, were used. Eighteen people were interviewed. Four business owners, as well as the project manager could be regarded as 'key informants', whom I met with at least twice. An ethnographically inspired component of this study (Alvesson and Sköldberg 1994, 
Alvesson and Deetz 2000) involved participant observations of eight meetings, one full day conference and one full day 'mini-exhibition', as well as social gatherings connected to these events. During one of my visits to Karlshöjden, I stayed there as a tourist for three days. I got to know the place, felt atmosphere, visited restaurants and had conversations with shopowners.

The interviews were conducted in three phases. In phase 1 (November 1997-February 1998) I interviewed the key informants, who were active both on the board of the tourism association and in the management group of the project - they were the project manager, three board members and one active participant. In my choice of four business owners, two were female and two male and each informant represented one of the four parts of the municipality of Karlshöjden. During phase 2 (May-August 1998) I obtained new perspectives from six new interviewees as well as returning to four of the key informants. This was necessary in order to see whether their views had changed. During phase 3 (January 1999), two out of four interviews were conducted with people I had previously interviewed. I had by then followed the project for one year and three months.

\subsection{The Tanzanian case}

To mitigate the problem of studying a different cultural context, I designed the Tanzanian study to enable as broad and rich an understanding of the context and the informal institutions as possible. The empirical study may be divided into three phases.

Phase 1 (April 1999-December 1999) was mainly devoted to understanding the context using an ethnographic inspired approach, making it necessary to learn the Swahili-language and interact with local people in everyday settings. Numerous unstructured dialogues focusing on 
cultural aspects were held in restaurants, bars and in people’s homes. This resulted in quite a profound understanding of the local context.

In phase 2 (January 2000-June 2000) around 40 interviews were conducted. Out of these, 20 interviews were allocated to four key informants. The informants were two male and two female participants of a business training scheme organized by the District and by the Tanzanian Chamber of Commerce Industry and Agriculture (TCCIA). These informants were visited five times each during Phase 2. Apart from these informants, the Executive Officer at TCCIA was an important informant, visited on almost a weekly basis. The interviews were semi-structured and often dictated by examples brought up by the informants. Dwelling upon examples of cooperation brought up by the interviewees was a deliberate strategy in order to grasp their reasoning around the abstract notion of trust. Moreover, between January and March there were many occasions for observing the business training sessions, as I was an advisor to the local District Council, which was one of the training organizers. These observations were not planned to be part of the study but contributed by adding confidence to the interview results.

In Phase 3 (during January 2001) the area was revisited. The focus then was on the emerging cooperation among business people in the town and their way of thinking about the change. Mr Mechack at the Chamber of Commerce, who had followed the developments during the autumn in real-time, was again an important source of information. The same applies to the two key informants who were available. The two others were not available during this period, and were substituted by close colleagues. 


\subsection{Reflections}

The ethnographically inspired approach in the empirical studies including socialising with local people and having local friends brought me close to the empirical contexts. In Tanzania, this approach enabled me to reach a rather deep understanding of the local 'rules of the game' for a mzungo (white person). However, a coin always has a flipside. The risk that I experienced with combining research with development work during the same period was that interviewees would have difficulty separating my role as a development worker and my role as a researcher. When visiting the business training scheme, the role was therefore solely as an observer. The trainers were advised at special meetings, and thus my role was not that of advisor or trainer in the class-room. I saw a potential risk that business owners could try to influence my view of their operations, hoping to obtain credit or other benefits from me and/or the project. I was very attentive to signals of such behaviour and in the selection of key informants an important criterion was their ability to understand the distinction between the two roles. In this selection process, I received advice from the Executive Officer of TCCIA as well as from other knowledgeable local colleagues. I carefully explained that discussions and interviews were not linked to the development programme and that information I was given about specific businesses and specific cooperation would not be forwarded to affect decisions there.

The linear image, promoted above to show the empirical phases, is not very informative either of the underlying research process or of how this paper has progressed. I would characterize the research process as abductive (Alvesson and Sköldberg 2000) involving the interplay of deductive and inductive phases. Continuous literature studies have helped me to gradually interpret existing field experiences. The two studies have of course many facets, and several interpretations and analyses are possible. Both cases are rendered at more length and in a 
narrative form elsewhere (Tillmar 2002). For reasons of space, I hereby draw on selected case material aimed at illustrating the third-order interpretation I have arrived at after working with the material for two years, leaving it for two years and then returning to it (cf. Alvesson and Sköldberg 2000).

During the research process, having been inspired by Molander (1993), I have alternated between focusing on part and whole, near and distant, as well as action (interviewing) and reflection (interpretation). Both empirical studies were carried out in different phases, allowing for longer periods of distance and reflection over the whole picture in between. This, in combination with the use of key informants, facilitated my return to the field to ensure that interpretations made were appropriate. Contrasting the two divergent contexts also enabled mirroring them in each other and arriving at re-interpretations. To mention an example, an initial interpretation was very critical to the project in Karlshöjden. Having understood the influence of the Jante law (to be explained below), the interpretation was modified, only to be further reinterpreted when faced with the comparison with Singida. Returning to this empirical material after two years of other work, I was once again able to understand new aspects, and could illuminate the role of necessity driven entrepreneurial trust creation.

In order to make these quite extensive studies comprehensible to the reader, and also to highlight the issues central to this particular paper, I have chosen to present the material in condensed form while inserting quotes which are generative in the theorising process. 


\section{Contrasting Cases}

\subsection{Karlshöjden, Sweden}

Karlshöjden is a small Swedish town whose centre comprises a Main Street and shops. The town feels like a combination of an idyllic spot and an old industrial community. Some houses are wooden and colourfully painted, whereas others are grey apartment complexes made of concrete. It is a town of contrasts. Apart from the town, the municipality of Karlshöjden includes the old industrial community Skogsby, stretching towards the highlands, as well as North Coast and South Coast. It is situated one hundred kilometres, about one and a half hours drive, from the regional capital. More than 25 percent of the 8000 inhabitants are employed by the municipal office and as many as 11 percent work for the large industrial company, according to official statistics. Some business owners have moved in from Stockholm as well as from the two larger towns in the region.

The project studied was an association of businesses in the tourism sector. These businesses had applied for and received funds for rural support from the EU. Such funds are not distributed directly to individual business owners. The aim of the EU-funded project was to market the area and the activities offered by the members of the association, in order to attract more tourists.

Conflicts between two main factions of business owners strongly influenced activities within the project. The two factions were represented by a powerful indigenous business owner and a 'newcomer' who had recently moved to Karlshöjden from a large town. The factions quarrelled about a number of different issues during the period, but the greatest conflict 
concerned a booking agency set up by the newcomer. The reason for this quarrel was that the indigenous business man ran a booking office with less advanced technical solutions.

That the formal procedures in the tourism association could be circumvented by some people is apparent in the following quote from one of these influential people. 'There are actually some statutes, but they... I can confirm that, not just anyone, but to get a decision to go in a certain direction if it is realistic. That is possible, even if it's not according to the statutes.' The informal hierarchy among people in the old industrial community surfaced. Many bore witness to the strong social control in the area. There were strong norms relating to, 'How you do and don't do things in Karlshöjden'. An indigenous business owner in Karlshöjden claimed that it is dangerous to be too proactive, 'You won't be popular'.

The Jante law is a well known norm in the Scandinavian context, and essentially it implies that 'you should never think that you are something or that you are better than us [the others]'. (It was enacted by the Danish-Norweigian author Aksel Sandemose in his 1933 novel En flykting krysser sitt spor.) Some business people in Karlshöjden can witness to the fact that you can lose customers if you buy too flashy-a-car. For this reason, they have chosen a more mundane model, which they always replace with a similar one in the same colour. That way, people may not notice that they can afford a new car. On one occasion I asked an active person local tourism sector what he would say if I asked him to make a list of all those factors which constrain trust and cooperation, and received the following illustrative and representative reply, 'Might I say JANTE to all of it?'. Someone else said, 'We've got God over everything here, Jante.' The mentality is said to make one steal looks at one another and be dishonest instead of being open and cooperative. 
There were preconceptions about 'locals' as well as 'new-comers', that constrained trust and cooperation. An influential person said that: 'Within the tourism association thoughts and ideas are conveyed. Newcomers have copied business ideas from there. So, I no longer engage in the tourism association.' On the other hand, it is said that 'it is the general opinion that when one looks at the ones who ... well, have been successful ... they've come from outside.' So-called 'new-comers' who had lived in Karlshöjden for more than ten years and tried to get into the community tell me that it is very difficult. They say things like 'It can be hellish for outsiders. They are seen as bloody Gothenburgers and I'm a country bumpkin from Jämtland' or 'I'm from Stockholm, which condemns me straight away down here.'

Other prejudices that influenced the cooperative project related to men and women. It was said that there was no counterbalance to a dominant man on the board, since there were too many women on the board. Many had the view that women operated their businesses as a hobby activity, without caring much for the result. 'There are far too many women here, in the sense that business is a way of making the time pass. It doesn't even have to provide an income; they are happy anyhow.' A business woman further explained the attitudes towards female business operators: 'Yes, if a man starts a business on Main Street, for example a record shop, then he gets a small setting up grant and people say: 'Great ... they've opened a shop. That's good.' On the other hand, if a girl should start for example a baby clothes shop ... then people would start to wonder how she was going to manage ... Hasn't she got small children? ... That's what it would sound like.'

Business owners in Karlshöjden also differ in their approach to their businesses. Some run businesses to get supplementary income or to be able to live a quiet life in the countryside, while others concentrate 100 percent on improving their business. One interviewee 
maintained: 'There is one category which want to live on what they've got and another category which wants to develop ...' The different approaches naturally affect the cooperation. 'If everyone had the same standards of professionalism and experience, the wheels wouldn't have to be greased so often.'

Three people were especially important for the development of the EU-project. The initiator was a strong driving force saying that 'this is how I make my money ... I want to improve things for everyone so that I can rake in my share later'. He was however, not uncontroversial, and belonged to one of the two factions of the project. The complementary roles of the diplomatic chairperson and the hard-working employed manager employed by the project were vital. Still, opinions differed regarding whether the project was successful or not. According to a number of interviewees there were few tangible results. By the end of the study, the disagreement regarding the booking agency had not been resolved. Yet some argued that bus trips to the town had increased during 1998. Others said that an attitudinal change had taken place. The changing views on cooperation were expressed clearly by interviewees and could also be observed during a mini-fair in March 1998. The business owners interacted cheerfully with each other and some disclosed information about prices for example, during this mini-fair. Three of the interviewees maintained that it had become more natural to advertise jointly and recommend one another than it used to be: 'One change of attitude is that people are much more open to cooperation. It comes quite naturally. So the project has been like a shove in the back, an alarm clock, which has shown by means of, for example, joint advertising, that it [cooperation] can achieve results.'

Two people, who did not take an active part in the project, reckoned that the association in general can fulfil a function when one needs to make contacts, but that the concrete 
cooperation takes place outside the association. That the project fulfilled that function was evident. For example, another cooperative venture called the Square Dance, spontaneously emerged among people belonging to one of the factions of the EU-funded project.

\subsection{Singida, Tanzania}

In terms of the number of inhabitants Singida with its 110000 inhabitants is a considerably larger town than Karlshöjden. It is the capital of the Singida region, situated in central Tanzania. Due to the defective infrastructure, Singida is however a remote town, since it is about twelve hours by car from the largest town of Dar es Salaam, and six hours from the town of Arusha. Apart from agriculture and livestock-keeping, commerce and trade are important sources of income in the region. Due to the widespread practice of diversification, each business owner is often involved in both the buying and selling of cash crops, transport and retailing. This applies also to the informants of this study. However, all operate small shops in Singida town dealing, for example, in stationery, spare parts, women's clothing and food respectively. Their main problems regarded high costs of transportation and lack of capital for investments. As the business owners point out themselves, these problems could be minimised through cooperation. Still, in the beginning of the study, practically all the business owners interviewed expressed very pessimistic views on cooperation. I was told by local trainers of the business scheme that seminars could not be organised around group discussions, since participants would not even exchange thoughts and ideas with each other.

None of the business owners interviewed trust the police or the courts. These institutions are referred to as corrupt, and not of any help in case of fraud. One interviewee stated: 'The police disturb completely! They move around in circles. He will favour one if he gets money, then he will receive money from the other and he will favour him. He will accept from the one who complains and from the other part as well. Ah ... they can not help anyone. Many people do 
not go to the police. Almost ... even if they did not exist we would just continue to live our lives.'

There are also prejudices against people of different tribes. The Chagas for example, are regarded as being unreliable, but competent in business. People of the indigenous tribe, the Nyaturu, are not viewed as competent in business. Due to mechanisms of sanctions and safeguarding of rights within the tribal communities, members of the Chaga tribe are able to cooperate. In case of fraud or cheating, the Chaga turn to the elected leaders in their local tribal organisation, or to the elders in their home region, for arbitration. This facilitates cooperation among Chagas. They explain: 'It is a very normal thing. It helps a lot due to the problems with the courts. Chagas will be afraid of running away with money because of this. It is easy to cooperate because he/she knows that this is a possibility.'

For business conflicts involving 'non-Chagas' it is much more complicated to find a mechanism of arbitration. During the period of study, business owners started to turn to the executive officer of TCCIA (Tanzanian Chamber of Commerce Industry and Agriculture) for advisory services in cases of conflict. Moreover, beliefs in witchcraft are widespread in all spheres of life in the Tanzanian society. This breeds uncertainty, suspicion and distrust. Rumours are widespread; for example, some bus-operators and one shop owner are said to have practised witchcraft in order to get rid of competitors. This creates a situation where people feel that: 'You have no faith, you never know.'

Also gender influences cooperation in various ways. Due to cultural norms men and women seldom talk to each other about business issues or socialise as colleagues. Neither women nor men trust the business competence of women. On the other hand, people argue that women 
are more committed and reliable than men. They cannot disappear or cheat anyone, since they have to stay and take care of their children. 'Women are more trustworthy than men. They are not courageous, they are afraid... They are afraid even to borrow and they try harder than men (to pay back). They have children. Where would they run away to?'

Business owners expressed a perceived obligation to reciprocate when others had acted cooperatively. If one did not reciprocate, the relationship would turn bad and then one would not be helped when in need. Women are said to cooperate more than men, since they need each other more. Young women were told that 'if you do not trust each other, you will not develop'. Compared to owners of larger businesses, small-business owners say they would not be able to develop without helping each other.

When discussing who to include in a cooperation, it was regarded important '... to understand a person and his weaknesses, commitment and habits. If his interest is to put money in his pockets or if he will take more wives and spend money at bars if he gets hold of money...'. However, such knowledge is difficult to obtain. When deciding who to include in a cooperative venture, people consider the assets in town of thepotential members': 'it was people who already had assets ... a house [...] this reduce the temptation to disappear'.

During the period of empirical study, cooperation was to a larger extent regarded as possible and new cooperation was established. This could be observed at the closing session of the training March 1, 2000, where the business owners, to the surprise of the trainers, had lively and open discussions and exchanged ideas. During spring 2000, Mama Mmari and Henry, eventually managed to mobilise fourteen business owners to start a Savings and Credit Cooperative Society (SACCO). 
The business training scheme contributed to this change. In general, the business owners, who often had only primary school education, broadened their horizons: 'We started to know other things after the training - about the market and the turnover of the business. Before, I just sat here. What ever my husband brought I thought it was OK. I sat and sold. Now I say myself that I need this and this. [...] I can see now what people like, I see what they ask for.

More specifically, learning accounting and writing of contracts facilitated cooperation. Many emphasised the importance of learning book-keeping, and argued that it facilitated control over the money and thus lowers the problem of trust: 'Accounts really lower the problem of trust. If you do not look very carefully, you can not do business with people.' With regard to learning to practice book-keeping, one business owner said: 'After the end of the training and after thinking about the things we learnt there, I think that cooperation is possible if you write a contract and everything to make sure that every member has his/her rights and he/she can withdraw if he/she thinks things are not good.'

An equally important impact of the training was that the business people got to know each other. The training enabled people of different tribes, as well as men and women, to meet and interact as colleagues. When some participants of the training course started the Savings and Credit Cooperative Society, men and women of various tribes were included. The female initiator said: 'I was familiar with [a male business owner] before the training, but just enough to say hi, not enough to discuss business issues with him. Now we have a reason to discuss. We started to know each other better after being together there at the seminars. Tarimo was in my discussion group. So, it was easy to start discussions with him.' 


\section{Re-contextualising Trust and Cooperation}

Let us recall that the rules of the game can be regarded as the soil out of which the tree of trust, and hence cooperation, grows. In some areas, the soil is more fertile than in others. But the soil also receives its nutrients from different sources in different contexts. Below, I compare and discuss the endowment of the different sources of nutrients in the two contexts, before reflecting on lessons learnt with regard to preconditions for the trust formation process.

Tanzania is a society in transition towards the post-traditional and modern or, expressed differently, towards a society where the aspect of Gesellschaft is becoming more salient relative to Gemeinschaft (Asplund 1991). Informal institutions have to a large extent been disrupted, but formal institutions have not become embedded and trusted by the citizens (Giddens 1990). The prevailing culture of distrust is thus not surprising (cf. Luhman 1979, Zucker 1996, Sztompka 1999 among others). A vicious circle is at hand, where the culture of distrust leads to negative effects on social stability, perceptions of accountability, people’s optimism and resources (cf. Sztompka 1999).

Business owners in Karlshöjden are working in a stable context, one where to a high extent the citizens trust the judicial system, the police and the government officials. These structural features can thus act as sources of basic trust in society (Shapiro 1987, Sztompka 1999). In addition, there is a free press able to examine the different institutions. The system builds on a paradox discussed by Sztompka (1998) which implies an institutionalisation of distrust for the sake of trust. In contrast to the people of Singida, people in Karlshöjden also enjoy a high standard of living and a social security system. Institutions enabling a Gesellschaft-oriented lifestyle are in place. Still, in the small industrial community, some informal institutions, such 
as the Jante law and scepticism towards newcomers, can be interpreted as a way of protecting remaining dimensions of Gemeinshaft.

With regard to informal institutions, there are surprisingly quite a number of similarities between the towns. Jealousy and fear constrained trust in both contexts. In neither of the towns did business owners disclose information about their incomes. An indigenous business owner in Karlshöjden explained that it is dangerous to be too proactive, 'You won't be popular'. Jealousy, combined with strong social control, made people hide things from each other. In Singida, these notions were expressed as, 'Especially if you succeed you will get problems. If you make a loss, they will be happy. It's a matter of jealousy and tribalism.' In Karlshöjden this informal institution is called the 'Jante law'. In Singida, the successful were more likely to be subject to witchcraft.

Both cases indicate that trust at the category level is of significant importance in the trust formation process and that it is influenced by informal institutions. Most apparent in these studies were the institutions of gender and ‘tribalism'. In Tanzania, women’s 'goodness’ (or benevolence) was trusted more than men's, but their competence was distrusted. Yet gender based stereotypes (Acker 1992, Ahl 2004) also affected trust development in the western context. In Karlshöjden, female business owners for example were not trusted to be committed to their business. Looking at the Tanzanian case, it was especially obvious how the development of trust between males and females was adversely affected by the fact that it was not accepted to socialise as colleagues. Common to both areas was also 'tribalism', in the sense that 'immigrant' business owners from other parts of the country were distrusted with regard to their goodness and 'locals’ were distrusted with regard to their competence. 
Comparing the two studies, it appears that while businesspeople in Singida face many severe institutional constraints on cooperation when compared with Karlshöjden, the difference in the amount of cooperation and trust is not as great as one might have expected. How can this be?

In the Tanzanian context, small business owners made entrepreneurial use of pre-existing 'rules of the game'. Traditional organisations, such as the tribal communities, were used in new ways for solving business conflicts. Their mechanisms of sanctions enabled some level of trust. The fact that women are fully responsible for their children was used as a natural situation of 'hostage' when female business owners were trusted on the basis that they could not easily disappear from the town. The same applies when business owners with fixed assets, like a house, were trusted since they would not benefit from disappearing from the town. In Karlshöjden, Sweden, such entrepreneurial trust creation was not observed. Cooperation was introduced top-down as a requirement in the tourism project, but it was possible to choose not to participate. The economic constraints were not as strong as in Tanzania.

From the comparison, I contend that when people in given situations perceive a sufficiently strong mutual need to cooperate, entrepreneurial activity is provoked and they may imaginatively create their own mechanisms to facilitate trust. This might be regarded as an example of community entrepreneurship being practised by far from privileged actors as part of their everyday life (Steyaert \& Katz 2004). While morality and norms of reciprocity for example are simultaneously present among the business owners (cf. Frank 1988, Solomon 1999) it is my interpretation that the main driving force behind entrepreneurial trust creation was a strong need. The lack of a sufficiently strong need to cooperate may thus explain why the project in Karlshöjden was characterised by conflict as much as by cooperation. 
Apart from pre-existing institutions, the tree of trust also received nutrients from the entrepreneurship of actors on the micro level. Inadequate institutions are not definite obstacles to cooperation, since people are entrepreneurial when it is needed. A third and important source of nutrient to the tree of trust, and to the rules of the game, should be added to figure 1 : entrepreneurship. The comparison suggests that such entrepreneurship may often be necessity driven.

This entrepreneurial trust creation does not occur in a vacuum. Inadequate formal institutions necessitated the action, and informal institutions such as tribal organisation and female responsibilities for children were drawn upon. The relationship between formal and informal/indigenous institutions has been discussed by many (North 1990, Berry 1993). There may be lock-in effects due to people being more used to the indigenous institutions (Havnevik and Hårsmar 1999), yet I contend that people use the mechanisms they need and can trust (cf. Giddens 1990). It would be in line with the findings here to suggest that, faced with changes in the formal institutional framework, informal institutions will also change.

In the meantime, entrepreneurial trust creation is important for breaking the vicious circles of distrust, since this trust creation enables cooperation. As cooperation and other kinds of interaction are initiated, trust is developed as a consequence (cf. also Gambetta 1988, Gulati 1995, Sztompka 1999). In Karlshöjden, the tourism association had the unintended consequence (Giddens 1984, Sydow 2000) of bringing the people together, leading to the start of the Square Dance initiative. In Singida, the business-owners met at the business training seminars and interacted across borders of tribe and gender to form a Savings and Credit Cooperative Society. 
The cases also illustrate how the rules of the game are transformed by interventions and entrepreneurship and that such transformation does not always take many years. In Tanzania, the business owner's perceptions of 'the rules of the game' at their disposal were limited. The training intervention proved suitable since it widened their frames of reference about business principles in general and book-keeping and contract writing in particular. This enabled them to make informed choices as to which rules of the game to act in accordance to. Knowledge of keeping records and writing contracts especially had immediate impact on the formation of a Savings and Credit Cooperative. New practices were also created, as the Chamber of Commerce took responsibility for solving business conflicts in Singida. In Karlshöjden, an attitudinal change took place and a wider circle of people around the enthusiasts entered into, or considered entering, some kind of cooperation. Yet, the changes in Karlshöjden were of a more minor character, arguably due to the lower need for cooperation.

\section{Contributions to Theory and Practice}

Through empirical examples from comparative longitudinal studies of two divergent contexts, this article has highlighted the importance of necessity driven entrepreneurial trust creation. In the terms of Child and Möllerings (2003), this article has illustrated strategies for active trust creation. However, it has also focused on the role of the institutional environment in which this process is embedded.

Many similarities between the contexts were found and perhaps surprisingly to the reader, Tanzanian entrepreneurship and Swedish ‘tribalism’ were observed. Similar informal institutions (prejudices based on gender and ‘tribalism' as well as jealousy) affect trust and 
cooperation in very different contexts. These were just manifested in somewhat different ways.

The studies suggest that entrepreneurship complements formal and informal institutions as nutrients to the tree of trust. The cases show how these three nutrients can substitute for each other. Studying only one, or even two, of these factors may thus give misleading results. The quality of the soil from which trust and cooperation are to grow is created by the local mix of the three nutrients and their interaction with each other. Due attention should thus also be given to informal institutions and entrepreneurial action in the trust creation process.

As to the possibilities of 'artificial fertilisation' of the tree of trust, the studies show that it has limited possibilities for success unless the need for cooperation is strong enough for the target group. This is a risk in top-down introduction of cooperation as in the EU-funded project in Karlshöjden. If the need exists however, opportunities for artificial fertilisation seem good. Creating arenas for business owners to meet and interact appear to be an especially suitable route towards facilitating the entrepreneurial trust creation process. Cooperation tends to emerge as an unintended consequence of other activities. Organising business training, as in the Tanzanian case, seems especially fruitful. The arena can then be managed in such a way as to maximise interaction between male and female business owners, as well as between people of different 'tribes'. In the development context, new rules of the game, such as contract writing and bookkeeping, may also be introduced.

Funds are allocated to the support of small-business cooperation through various projects and organisations both in the west and in developing countries, not least for purposes of regional development. Are the local prerequisites, in terms of the rules of the game, taken into due 
consideration in the majority of all these initiatives? I hope that this article has illustrated the importance of doing so.

With regard to methodology, contrasting two divergent contexts enabled both a deeper understanding of the contexts in themselves and a comparison revealing both differences and similarities. The methodology is rare in the literature on trust and cooperation. I contend that further comparative in-depth studies into the role of rules of the game in the trust creation process in differing contexts would be a fruitful route towards an understanding of the contextuality of trust, and hence of business cooperation. 


\section{References}

Acker, J. 1992 Gendering Organizational Theory, Gendering Organizational Analysis. (Newbury Park: Sage).

Ahl, H.J. 2004 The scientific reproduction of gender inequality: a discourse analysis of research texts on women's entrepreneurship (Stockholm: Liber; Copenhagen Business School Press).

Alvesson, M. and Lindkvist, L. 1993 Transaction Cost, Clans and Corporate Culture, Journal of Management Studies, 30(3): 427-452.

Alvesson, M. and Sköldberg, K. 2000 Reflexive Methodology: New Vistas for Qualitative Research (London: Sage Publications).

Asplund, J. 1991 Essä om Gemeinschaft och Gesellschaft (Göteborg: Bokförlaget Korpon).

Bachmann, R. (2000) Conclusion: Trust-Conceptual Aspects of a Complex Phenomenon, Trust within and between organizations: Conceptual Issues and Empirical Applications (Oxford: Oxford University Press).

Bachmann, R. 2003 The role of trust and power in the institutional regulation of territorial business systems, Cooperation, networks and institutions in regional innovation systems (Northhampton, MA: Edward Elgar).

Berry, S. 1993 No Condition Is Permanent: The social dynamic of agrarian change in subSaharan Africa (Wisconsin: The University of Wisconsin Press).

Brislin, R.W., Lonner, W.J. and Thorndike, R.M. 1973 Cross-Cultural Research Methods (New York: Jon Wiley \& Sons).

Burt, R.S. and Knez, M. 1996 Trust and Third-Party Gossip, Trust in Organizations: Frontiers of Theory and Research (London: Sage Publications).

Child, J. and Möllering, G. 2003 Contextual Confidence and Active Trust Development in the Chinese Business Environment, Organization Science, 14(1): 69-80.

Child, J. 2000 Trust and International Strategic Alliances: The case of Sino-Foreign Joint Ventures, Trust within and between organizations: Conceptual Issues and Empirical Applications (Oxford: Oxford University Press).

Coleman, J.S. 1988 Social Capital in the Creation of Human Capital, American Journal of Sociology, 94 Supplement: S95-S120.

Deakin, S. and Wilkinson, F. 2000 Contract Law and the Economics of Interorganizational Trust, Trust within and between organizations: Conceptual Issues and Empirical Applications (Oxford: Oxford University Press). 
Frank, R.H. 1988 Passions Within Reason: The Strategic Role of the Emotions (New York: W. W. Norton).

Fukuyama, F. 1996 Trust: Social Virtues and the Creation of Prosperity (London: Penguin Books).

Gambetta, D. 1988 Can We Trust Trust? Trust: Making and breaking cooperative relations (Oxford: Basil Blackwell).

Giddens, A. 1984 The constitution of society (Cambridge: Polity Press).

Giddens, A. 1990 The consequences of modernity (Cambridge: Polity in association with Blackwell).

Granovetter, M. 1985 Economic Action and Social Structure: The Problem of Embededness, American Journal of Sociology, 91(3): 481-510.

Gulati, R. 1995 Does Familiarity Breed Trust? The Implications of Repeated Ties for Contractual Choice in Alliances, Academy of Management Journal, 38(1): 85-112.

Hagen, J.M. and Choe, S. 1998 Trust in Japanese Interfirm Relations: Institutional Sanctions Matter, Academy of Management Review, 23(3): 589-600.

Havnevik, K. and Hårsmar, M. 1999 The diversified future - An Institutional Approach to Rural Development in Tanzania (Stockholm: Almqvist \& Wiksell International).

Håkansson, H. and Snehota, I. 1995 Developing Relationships in Business Networks (London: International Thomson Business Press).

Johannisson, B. 2002 The Power of Networking in the Entrepreneurial Process, Entrepreneurship in Emerging Economies: The Creation and Development of New Firms in Latin America and East Asia (Washington DC: Inter-American Development Bank).

Johannisson, B. 1995 Livsverk \& Affärsverk: Kvinnors bruk av personliga nätverk $i$ företagarkarriären, Pengarna och livet: Perspektiv på kvinnors företagande (Stockholm: NUTEK).

Lewicki, R.J. and Bunker, B.B. 1995 Trust in Relationships: A Model of Development and Decline, Conflict, cooperation and justice (San Francisco: Jossey-Bass).

Lewis, J.D. and Weigert, A. 1985 Trust as a Social Reality, Social Forces, 63(4): 967-985.

Luhmann, N. 1979 Trust and Power (New York: John Wiley \& Sons Ltd).

Maguire, S., Phillips, N. and Hardy, C. 2001 When Silence = Death, Keep Talking: Trust, Control and the Discursive Construction of Identity in the Canadian HIV/AIDS Treatment Domain, Organization Studies: Special Issue on: Trust and Control in Organizational Relations, 22(2): 285-310. 
Maillat, D. 1995 Territorial dynamic, innovative milieus and regional policy, Entrepreneurship \& Regional Development, 7: 157-165.

Molander, B. 1993 Kunskap i handling (Göteborg: Daidalos).

Nooteboom, B. 1996 Trust, Opportunism and Governance, A Process and Control Model, Organization Studies, 17(6): 985-1010.

North, D.C. 1990 Institutions, Institutional Change and Economic Performance (Cambridge: Cambridge University Press).

Pettersson, M. 1999 Förtroende i samverkan: en studie av småföretagare i ett regionalt utvecklingsprojekt, Department of Management and Economics (Linköping: Linköpings Universitet).

Powell, W.W. 1996 Trust-Based Forms of Governance, Trust in organizations: Frontiers of theory and research (London: Sage Publications).

Putnam, R.D. 1993 Den fungerande demokratin: Medborgarandans rötter i Italien (Stockholm: SNS Förlag).

Ragin, C.C. 1989 The Comparative Method - Moving Beyond Qualitative and Quantitative Strategies (Los Angeles: University of California Press).

Ring, P.S. 1996 Fragile and Resilient Trust and their Roles in Economic Exchange, Business and Society, 35(2): 148-175.

Rousseau, D.M., Sitkin, S.B., Burnt, R.S. and Camerer, C. 1998 Introduction to Special Topic Forum - Not so Different After All: A Cross Discipline View of Trust, Academy of Management Review, 3(3): 393-404.

Sandemose, A. 1933/1977 En flykting korsar sitt spår (Uddevalla: Forum).

Saxenian, A. 1994 Regional advance: culture and competition in Silicon Valley and Route 128 (Cambridge MA: Harvard University Press).

Schumpeter, J.A. 1934/1994 The theory of economic development, Om skapande förstörelse och entreprenörskap: I urval av Richard Swedberg (City University Press/ Stockholm: Ratio).

Shapiro, D.L., Sheppard, B.H. and Cheraskin, L. 1992 Business on a handshake, Negotiation Journal, 8: 365-377.

Sitkin, S.B. 1995 On the Positive Effects of Leganlization on Trust, Research on Negotiation in Organizations, 5: 185-217.

Solomon, R.C. 1999 A Better Way to Think About Business: How Personal Integrity Leads to Corporate Success (New York: Oxford University Press).

Stewart, R., Barsoux, J.-L., Kieser, A. and Walgenbach, P. 1994 Managing in Britain and Germany (New York: St. Martin’s Press). 
Sydow, J. 2000 Understanding the Constitution of Interorganizational Trust, Trust within and between organizations: Conceptual Issues and Empirical Applications (Oxford: Oxford University Press).

Szarka, J. 1990 Networking in Small Firms, International Small Business Journal, 8(2): 1022.

Sztompka, P. 1999 Trust: A Sociological Theory (Cambridge: Cambridge University Press).

Steyaert, C. and Katz, J. 2004 Reclaiming the space of entrepreneurship in society: geographical, discursive and social dimensions, Entrepreneurship \& Regional Development, 16(May): 179-196.

Sztompka, P. 1998 Trust, Distrust and Two Paradoxes of Democracy, European Journal of Social Theory, 1(1): 19-32.

Tillmar, M. 2002 Swedish Tribalism and Tanzanian Agency: Preconditions for Trust and Cooperation in a Small-Business Context, Department of Management and Economics/Business Administration (Linköping: Linköping University).

Tillmar, M. and Lindkvist, L. 2005 Cooperation against all odds, paper presented at the Academy of Management Meeting. Honolulu, $5^{\text {th }}-10^{\text {th }}$ August.

Worldbank 2001 Aid and Reforms in Africa: Lessons from Ten Case Studies (Washington DC: Online Media Briefing Center).

Zucker, L.G. 1986 Production of Trust, Institutional Sources of Economic Structure 18401920, Research in Organizational Behavior, 8: 53-111.

Zucker, L.G., Darby, M.R., Marilynn, B.B. and Yusheng, P. 1996 Collaboration Structure and Information Dilemmas in Biotechnology: Organizational Boundaries as Trust Production' Trust in Organizations: Frontiers of Theory and Research (London: Sage Publications).

\section{Acknowledgements}

The author acknowledges the valuable comments of Professor Bengt Johannisson and two anonymous reviewers. 


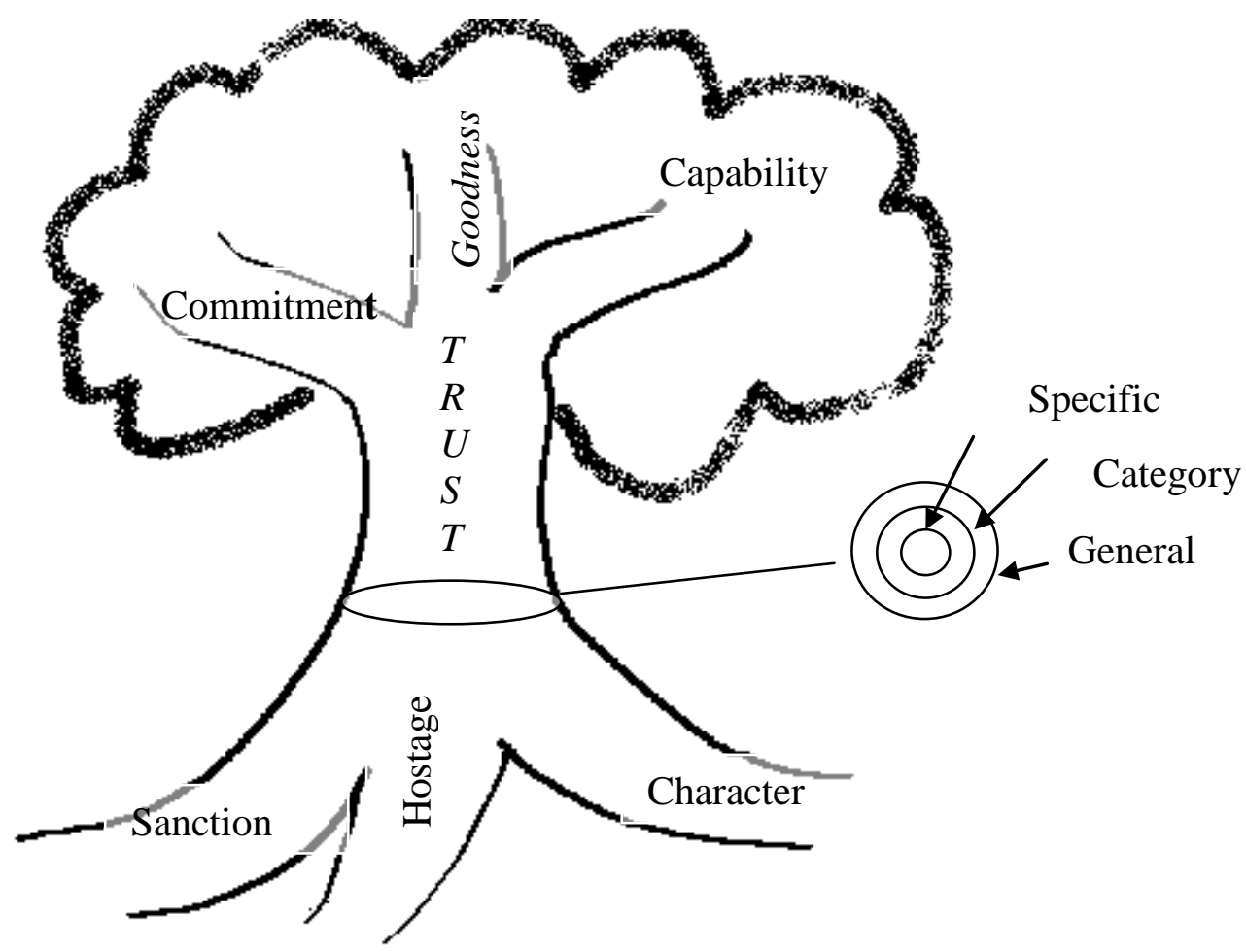

Formal institutions

Informal Institutions

Objects

\section{Focal levels}

Reasons

Rules

of the

Game

Figure 1: The $\mathrm{t}(\mathrm{h})$ ree dimensions of trust.

\footnotetext{
${ }^{\mathrm{i}}$ The two latter reasons for trust may be perceived as linked to control. Within trust research, there is avid debate on the relationship between trust and control which is outside the scope of this paper. For an elaboration on my view of this contingent relationship I refer to Tillmar and Lindkvist (2005).
} 